\title{
Effect of Students' Feedback and Academic Discipline of Teachers on Teacher Adjustment of Secondary School Teachers
}

\author{
Sunil Kumar \\ (Drona College Of Education, Gurgaon, Haryana.India)
}

\begin{abstract}
The present study was aimed at finding the Effect of Students' Feedback and Academic Discipline of Teachers on Teacher Adjustment of Secondary School Teachers. This study was experimental in nature. Sample comprised of 102 Secondary School Teachers teaching in different five schools of Rewari city and students taught by them. In the Experimental group after taking students appraisal data of teacher effectiveness feedback was given to the teachers by the researcher. This Students' feedback was comparative and non comparative, overall and dimension wise. It also included suggestions elicited from the students on important aspects of their teaching. The present study found no significant effect of Students' Feedback on Teacher Adjustment. Also, Teacher Adjustment was independent of Academic Discipline of Teachers as well as the interactional effect of Academic Discipline of Teachers and Students' Feedback, when Pre-Teacher Adjustment was taken as covariate.
\end{abstract}

Keywords: Teacher Adjustment, Students' Feedback, Academic Discipline

\section{Introduction}

Teachers are in most strategic position to facilitate a balanced personality development and a more adequate adjustment of the learner. The teacher's own adjustment not only contributes to better adjustment of students but is essential for his own efficiency and happiness (pal,2002). A maladjusted teacher not only destroys his own professional life but also ruins his or her students' life. Teachers who are competent and emotionally mature make the total school atmosphere full of learning experience for the students. On the other hand incompetent and maladjusted teacher spoil the school atmosphere. Unsatisfied frustrated teachers cannot make students happy and well adjusted in the school (Yadav,2006). Teachers should be mentally alert and stable to develop alertness and stability in students. Teachers' behavior will reflect students' behavior.

\section{Students' Feedback And Adjustment Of Teachers}

Students' feedback is actually a reflection of teachers' adjustment (Prasad,2004). Student Feedback to their Teachers contributes significantly to improvement of teaching quality (Nitza and Dan ,2006).The personality of well adjusted teacher remains vital experience for the students to examine and imitate. They consider these teachers effective and always appraise them with positive feedback. On the other hand students dislike those teachers who are frustrated and unsatisfied. Maladjusted teachers seem to fail in making positive relationship with their students and got negative feedback from their students.

Also, teachers who have well adjustment in schools accepted feedback positively and teachers maladjusted take feedback information negatively (Donga,1987). Thus Feedback providing to teachers got affected through their adjustment. But after having knowledge of self strength and weak points from their own taught, do the teachers try to improve their teaching practice? And does this improvement (through feedback) will have any impact on their adjustment? Does Academic background (Discipline) of teachers play crucial role for accepting feedback and to adjust with their circumstances? These research questions were focus of the present study.

Objectives of The Study

1. To study the effect of Students' Feedback on Teacher Adjustment by taking Pre-Teacher Adjustment as covariate.

2. To study the effect of Academic Discipline of teachers on Teacher Adjustment by taking Pre-Teacher Adjustment as covariate.

3. To study the interactional effect of Students' Feedback and Academic Discipline of teachers on Teacher Adjustment by taking Pre-Teacher Adjustment as covariate.

\section{Hypothesis Of The Study}

1. There is no significant effect of Students' Feedback on Teacher Adjustment by taking Pre- Teacher Adjustment as covariate.

2. There is no significant effect of Academic Discipline of teachers on Teacher Adjustment by taking PreTeacher Adjustment as covariate. 
3. There is no significant effect of Students' Feedback and Academic Discipline of teachers on Teacher Adjustment by taking Pre- Teacher Adjustment as covariate.

\section{Sample}

The study was experimental in nature. The sample comprised of 102 higher secondary school teachers belonging to five different schools of Rewari city and also the students being taught by these teachers were taken as sample in the present study. These schools were selected by purposive sampling technique. All schools were situated in Rewari city and were following CBSE syllabus and co-educational system. Out of these five schools treatment was assigned randomly to the three schools. These three schools fell under Experimental Group and other two schools were taken as Control Group. There were 19 Science discipline teachers and 36 Non-Science discipline teachers in the experimental group. On the other hand, 22 Science discipline teachers and 25 Non Science discipline teachers were there in Control group. Thus total 41 Science discipline teachers and 61 Non Science discipline teachers were in the sample of this present study. Group-wise and Academic Discipline-wise distribution of teachers is given below under table 2 .

Table 2 Group wise and Academic Discipline wise distribution of sample

\begin{tabular}{cccc}
\hline \multirow{2}{*}{ Group } & \multicolumn{2}{c}{ Academic Discipline } & Total \\
\cline { 2 - 4 } & Science & Non Science & 55 \\
Experimental & 19 & 36 & 47 \\
Control & 22 & 25 & 102 \\
\hline Total & 41 & 61 & \\
\hline
\end{tabular}

\section{Tools Used}

Adjustment of the teachers was assessed with a standardized tool namely Mangal Teacher Adjustment Inventory (Short Form) (MTAI) by Dr, S.K. Mangal published by National Psychological Corporation, Agra in 2007. The reliability of the tool was examined through test-retest method and spilit half method. The reliability coefficients obtained through these methods were 0.96 and 0.98 respectively. The validity for the inventory has been established by adopting criterion related approach and percentile norms were also computed. Students' Feedback was based on Scores of Teacher Effectiveness Scale (TES) which was developed by the researcher. This feedback was comparative and non comparative, overall and dimension wise graphical presentation of TES scores. It also included suggestions elicited from the students on important aspects of their teaching.

\section{Analysis and Interpretation Of Data}

The data were analyzed with the help of $2 \times 2$ Factorial Design ANCOVA. There were two levels of Students' Feedback namely Students' Feedback and No Students' Feedback. First level Students' Feedback was taken as Experimental Group and second level No Students' Feedback was taken as Control Group in the study. There were 55 teachers in Experimental Group and 47 teachers were taken under Control Group. The results are given in following table 2 :

Table 2 Summary of 2x2 Factorial Design ANCOVA for Teacher Adjustment by taking Pre-Teacher Adjustment score as co-variate

\begin{tabular}{|c|c|c|c|c|}
\hline Source of Variance & Df & SS y.x & MSS y.x & F y.x \\
\hline Students' Feedback & 1 & 12.241 & 12.241 & 0.776 \\
\hline Academic discipline of teachers & 1 & 0.621 & 0.621 & 0.039 \\
\hline $\begin{array}{l}\text { Students' Feedback x Academic } \\
\text { discipline of teachers }\end{array}$ & 1 & 3.684 & 3.684 & 0.234 \\
\hline Error & 97 & 1530.366 & 15.777 & \\
\hline Total & 100 & & & \\
\hline
\end{tabular}

From table 2, it can be seen that the adjusted F-value for Students' Feedback is 0.776 which is not significant. Therefore, the null hypothesis that there will be no significant effect of Students' Feedback on Teacher Adjustment when Pre-Teacher Adjustment was taken as co-variate is not rejected. It can thus be concluded that the Teacher Adjustment is independent of Students' Feedback when Pre-Teacher Adjustment was taken as co-variate.

Again from table 2, it can be seen that the adjusted F-value for Academic discipline of teachers is 0.039 , which is not significant. Therefore, the null hypothesis that there is no significant effect of Academic discipline of teachers on Teacher Adjustment when Pre-Teacher Adjustment was taken as co-variate is not rejected. It can thus be concluded that the Teacher Adjustment is independent of Academic discipline of teachers when Pre-Teacher Adjustment was taken as co-variate.

Once again from table 2, it can be seen that the F-value for the interaction between the Students' 
Feedback and Academic discipline of teachers is 0.234 , which is not significant. Therefore, the null hypothesis that there is no significant effect of interaction between Students' Feedback and Academic discipline of teachers on Teacher Adjustment when Pre-Teacher Adjustment was taken as co-variate is not rejected. It can thus be concluded that the Teacher Adjustment is independent of interaction between Students' Feedback and Academic discipline of teachers when Pre-Teacher Adjustment was taken as co-variate.

\section{Findings and Discussion}

The findings of the study were as follows:

- Teacher Adjustment was independent of Students' Feedback, when Pre- Teacher Adjustment was taken as co-variate.

- Teacher Adjustment was independent of Academic Discipline of teachers when Pre- Teacher Adjustment was taken as co-variate.

- Teacher Adjustment was independent of interaction between Students' Feedback and Academic Discipline of teachers when Pre- Teacher Adjustment was taken as co-variate.

The study revealed no significant effect of Academic Discipline of teachers on Teacher Adjustment when Pre-Teacher Adjustment was taken as co-variate. Teachers belonging to Science Discipline and Non Science Discipline were found to have similar Adjustment scores when groups were matched with respect to Pre-Teacher Adjustment. It reveals that Adjustment of teachers belonging to Science Discipline and Non Science Discipline did not differ significantly when groups were equated with respect to Pre-Teacher Adjustment scores. Among the researches reviewed by the researcher not many had been conducted to explore the relationship between teacher Adjustment and academic discipline of teacher.

The result obtained by the researcher in the present study can be justified by the fact that in schools generally there are same teaching hours, same students, similar level of course content and same routine of examination or tests is being handled by all the teachers. Where on one side science faculties have to handle the responsibilities of science laboratories, on other side non science teachers also have to handle the responsibilities of co-curricular activities. Further many responsibilities of school like Scout and guide, discipline, furniture maintenance, resource room, teaching aid room, sports etc are being given to all the teachers in the school regardless keeping in mind their academic discipline, All have to face many difficulties, challenges and adjustment problems and in spite of so many challenges it is the prime responsibility of a teacher to motivate their students to achieve desired result and also all teachers have to devote same efforts to give better result in favor of school regardless their discipline. This may be the reason for finding independence of teacher adjustment from their academic discipline.

The study also revealed Teacher Adjustment is independent of interaction between Students' Feedback and Academic Discipline of teachers when Pre-Teacher Adjustment was taken as co-variate. This shows that among feedback group, teacher Adjustment scores of teachers with Science background was not significantly different from Non Science background teachers. The same could be said about the no feedback group meaning thereby that levels of students' feedback and levels of academic discipline of teachers are independent of each other in respect of teacher Adjustment when groups were matched with respect to Pre-Teacher Adjustment.

\section{Concluding Remarks}

In the present study Teacher Adjustment of Teachers was found independent of Students' feedback, Academic Discipline of teachers and also from their interaction. As the studies related to same aspect are either very few or not giving strong support to the finding of present study, there is need to do further research in this direction.

\section{References}

[1] Best,J.W. and Khan, J.V. (2002): Research in Education. Prentic hall of India Pvt.Ltd., New Delhi.

[2] Buch M.B. (ed.)(1983-88): Fourth Survey of Research in Education, Vol. I \& II, New Delhi, NCERT.

[3] Crow and Crow (1951) : Mental hygine Mc Grow Hall book company Toranto London.

[4] Donga, N. S. (1987): A study of the Adjustment of Trainees of Teacher Training Colleges in Gujrat, in Buch, M.B.(ed.)Fourth Survey of Research in Education, Vol. II (1983-88). New Delhi, NCERT. p 933

[5] Mangal,S.K.(2007): Mangal Teacher Adjustment Inventory(Short Form) (MTAI). National Psychological Corporation, Agra.

[6] Nitza, D.; Dan, S. (2006): Using Students' Assessments to Improve Instructors' Quality of Teaching. Journal of Further and Higher Education, 30(4).p351-376.

[7] Pal, B. K.(2002) : A Study of Core Teaching Skills of In-Service Primary Teachers in relation to their Self- concept and Adjustment.

[8] Prasad S.( 2004): A study of Psycho-Social Factors of Adjustment problems of Primary School Teachers of Garhwal Mandal. HNB Garhwal University, Srinagar (Garhwal), Uttaranchal

[9] Yadav, R. C. (2006): A Comparative Study of Adjustment of Secondary School Teachers. 